\title{
How familiar are we with decision-making concerning the treat- ment of perforation after endoscopic mucosal resection (EMR) in the colon? A case report
}

\section{(ㄷ)(i) $\Theta$}

\author{
Authors \\ Institutions \\ 1 Department of Gastroenterology, Linköping University \\ Hospital, Linköping, Sweden \\ 2 Department of Clinical Pathology, Linköping University \\ Hospital, Linköping, Sweden
}

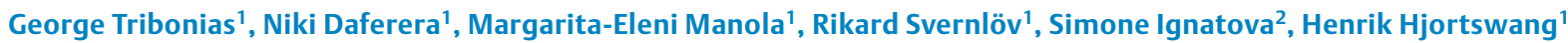

submitted 17.7 .2017

accepted after revision 27.10 .2017

\author{
Bibliography \\ DOI https://doi.org/10.1055/s-0043-123932 | \\ Endoscopy International Open 2018; 06: E308-E312 \\ (c) Georg Thieme Verlag KG Stuttgart · New York \\ ISSN 2364-3722
}

Corresponding author

George Tribonias, Department of Gastroenterology,

Linköping University Hospital, Universitetssjukhuset 581

85, Linköping, Sweden

g.tribonias@gmail.com

\section{ABSTRACT}

Background and study aims We describe a case of perforation after colonic endoscopic mucosal resection (EMR) that was treated conservatively. We would like to highlight the importance of decision-making mainly based on the endoscopist's point of view in combination with the surgical consultation. Although the radiological imaging is always needed, it cannot solely lead to a decision for operation. Intraperitoneal gas in computed tomography is not always associated with a hole in the endoscopic field and could be possibly explained from a "balloon" phenomenon. The amount of extraluminal air after an EMR does not correlate reciprocally with patient's pain after the procedure. Even though perforation is a radiological diagnosis and endoscopists should be aware of the common post-EMR radiological findings, the surgical examination is mandatory and should be coupled with the endoscopic opinion in order to guide appropriately the treatment in patients with acute pain.

\section{Introduction}

Endoscopic mucosal resection (EMR) in a tertiary setting is the treatment of choice for large sessile polyps and laterally spreading tumors (LSTs) in the colon. It is a safe, efficient and effective technique as an alternative to invasive surgery for the treatment of large or complex colorectal polyps [1,2]. In this case report we describe a patient, who developed severe abdominal pain post-EMR with positive imaging finding for perforation and was treated conservatively. A decision-making algorithm starting from the endoscopist's point of view but taking into major consideration the surgical consultation is crucial for an effective stratification in order to avoid unnecessary surgery.

\section{Case Report}

A 76-year-old male with previous right hemi colectomy due to colorectal cancer underwent scheduled EMR for a 35-mm distal sigmoid colonic polyp (Paris classification 0-Ila + Ilc, Nice classification II and focally III, LST - granular/G type, subtype/nodular mixed type, - Fig.1). A standard EMR technique was used for removing the polyp with good endoscopic result (Ro resection - no endoscopically observed residual adenoma, > Fig. 2). The patient developed severe hypotension $(65 / 30 \mathrm{mmHg})$ immediately after the procedure that was effectively treated with normal saline infusion. When the patient was recovering from the hypotension episode, he experienced severe abdominal pain in the left lower quadrant radiating towards the middle of the lower abdominal cavity. An urgent computed tomography (CT) of the abdomen demonstrated that the sigmoid colon distally and closely to the recto-sigmoid junction was distended with gas. In and over the recto-sigmoid junction there was dif- 

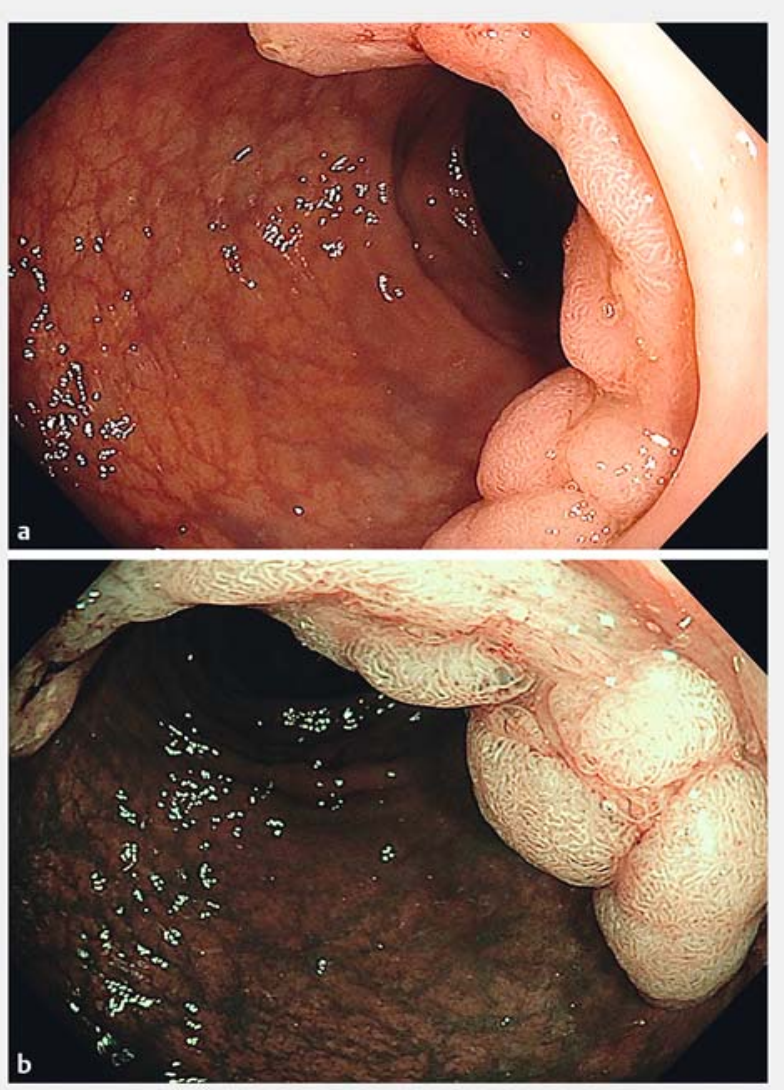

- Fig. 1 A 35-mm flat lateral spreading tumor (LST) in sigmoid coIon with Paris classification 0-Ila + Ilc, Nice classification II and focally III, LST - granular/G type, subtype/nodular mixed type, under white light (WL, a) and narrow band imaging (NBI, b) endoscopy.

fuse transmural thickening and edema ( $\triangleright$ Fig.3). There was evidence of intramural air bubbles and a single, extraluminal, $1-\mathrm{cm}$ air bubble just adjacent to the colonic wall ( $\triangleright$ Fig.3). There was some stranding in the adjacent fat. There was no evidence of any free air or free liquid and the remaining abdominal organs were normal.

A diagnosis of covered perforation of the colon was established. Taking into consideration the surgical consultation for the patient, the CT imaging and the absence of endoscopic suspicion of a true perforation, the patient was managed conservatively with bowel rest, intravenous fluids, antibiotics and analgesia. The pain settled after 6 hours and the patient was closely observed for 12 more hours. From this point, the patient remained absolutely pain free with clinical observations within the normal limits. Blood work revealed slightly elevated white blood cells and CRP. Oral intake of food recommenced with good response and the patient was discharged 3 days later. Histology confirmed tubulovillous adenoma with high-grade dysplasia ( $>$ Fig.4). A second question to the pathologists was made concerning the presence of cut or damaged muscularis propria (MP) in the specimen relevant with deep injury of the bowel wall during EMR, with a negative answer ( $>$ Fig.4).
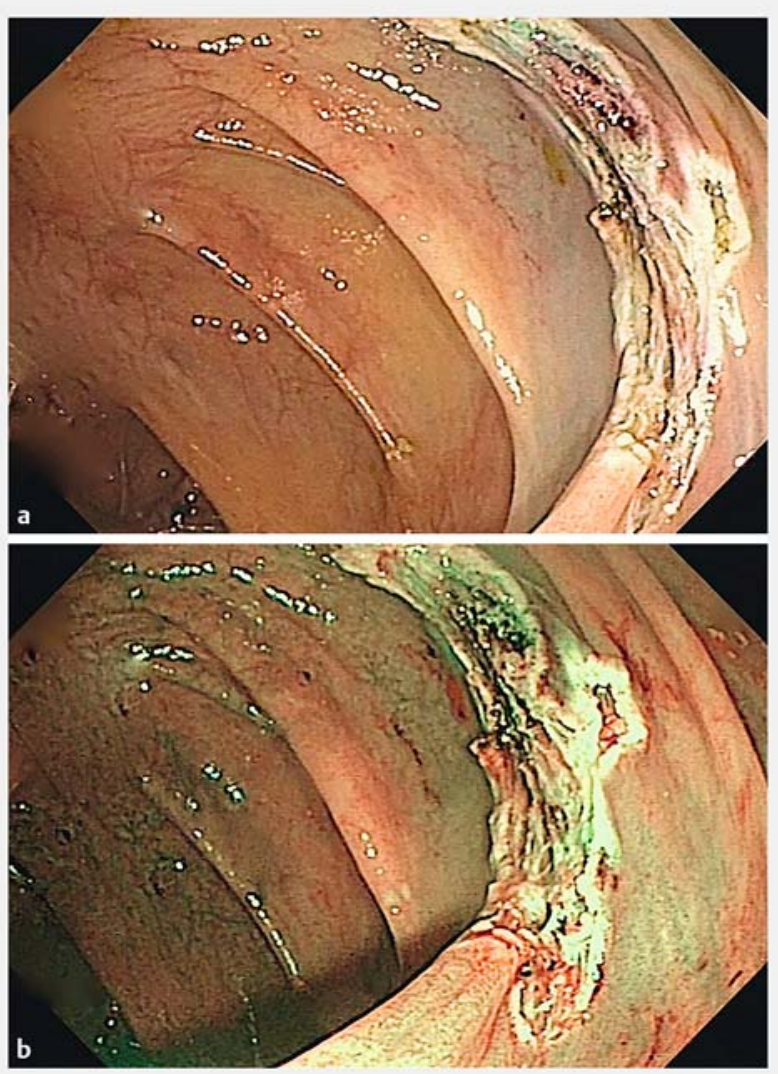

- Fig. 2 The resulting defect after endoscopic mucosal resection (EMR) of the sigmoid polyp with endoscopic appearance for complete eradication - Ro resection (no endoscopically observed residual adenoma) as viewed with WL (a) and NBI (b) endoscopy. Sydney classification for deep mural injury (DMI) after careful observation of the lesion revealed DMI type 2 with a central 1-point unclear distinction between submucosa and MP, otherwise with the exposed muscle layer seemed to be uninjured.

\section{Discussion}

latrogenic perforation of the colon related to EMR therapeutic interventions is a rare, but severe adverse event. The multicenter Munich Polypectomy Study (MUPS) with 3976 snare polypectomies showed a perforation risk of $1.1 \%$ [3]. Specific procedural related factors increase the risk of major complications (perforation and bleeding), such as sessile and flat polyps, lesions $>20 \mathrm{~mm}$ in size or located in the right colon [3].

Radiologically, CT is the gold standard in recognizing presence of free air in the peritoneal cavity. On the CT findings of perforation generalized pneumoperitoneum or a localized collection of intra-peritoneal gas associated with the site of EMR, are commonly seen. It could also reveal free fluid with inflammatory stranding in the surrounding mesenteric fat, signs of peritoneal contamination that require urgent surgical consultation and possible restoration [4]. An effective algorithm on decision-making for the treatment of perforation seems to be crucial, when $\mathrm{CT}$ findings confirm the diagnosis of perforation, which could be linked to significant morbidity and mortality. 

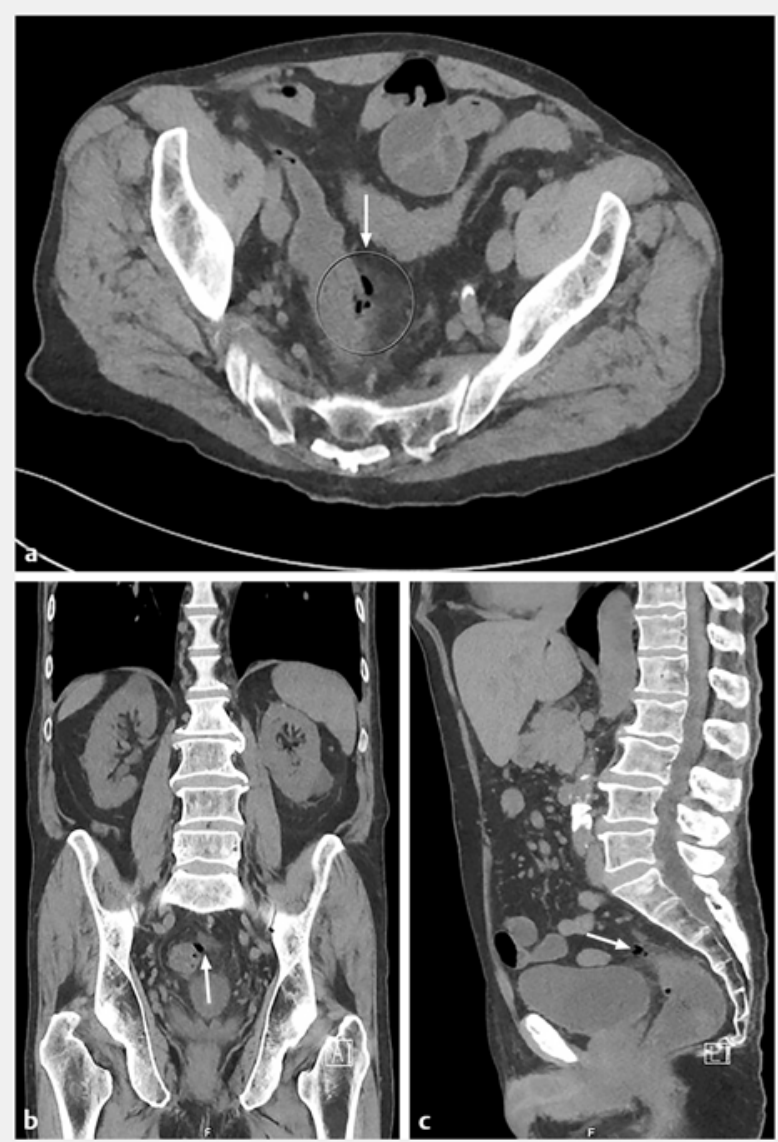

- Fig. 3a, b, c Computed tomography imaging of the abdomen demonstrated intramural air, a unique bubble of extraluminal gas, and inflammatory fat stranding (a) at the site of the polyp removal with endoscopic mucosal resection (EMR) in the sigmoid colon. The features were consistent with a covered colonic perforation.

In our case report, the post-EMR defect was closely observed in detail with an endoscopic aspect about Ro resection and DMI type 2 (Sydney Classification for Deep Mural Injury [5]) with a one-point unclear distinction between submucosa and MP. The exposed muscle layer seemed to be uninjured and clear evidence of endoscopic perforation with target sign (DMI type 3) or visible hole (DMI type 4) were not recognized [5]. No clipping appliance decided due to the absence of the previously mentioned signs.

The EMR technique requires submucosal injectate that pushes over the mucosal layer, elevates the polyp and increases the depth between the mucosa and the outer bowel wall allowing the polyp to be excised without perforation. There is a previously reported case in the literature with positive radiological sign of free air into the peritoneal cavity, but without endoscopic clear sign of perforation, where the authors developed the theory for the leakage of insufflated air or $\mathrm{CO}_{2}$ following a transmural passage of the EMR needle [6]. In our patient, the radiological findings revealed a minimal $1 \mathrm{~cm}$ bubble of extraluminal air at the site of EMR. The absence of endoscopic sign suspicious for perforation support the hypothesis for: 1) Leak-
- Table 1 Symptoms, endoscopic and radiological findings in patients with intramural/extraluminal gas but no endoscopic signs of perforation after endoscopic mucosal resection (EMR) in colonic polyps.

\begin{tabular}{|c|c|c|c|}
\hline $\begin{array}{l}\text { Clinical manifesta- } \\
\text { tions }\end{array}$ & $\begin{array}{l}\text { Stephenson } \\
\text { et al. [4] }\end{array}$ & $\begin{array}{l}\text { Heerasing } \\
\text { et al. [6] }\end{array}$ & $\begin{array}{l}\text { Tribonias } \\
\text { et al. }\end{array}$ \\
\hline $\begin{array}{l}\text { Abdominal pain after } \\
\text { EMR }\end{array}$ & +++ & + & +++ \\
\hline $\begin{array}{l}\text { Focalized abdominal } \\
\text { tenderness }\end{array}$ & ++ & - & ++ \\
\hline $\begin{array}{l}\text { Spontaneously recov- } \\
\text { ery from pain }\end{array}$ & No & Yes & No \\
\hline $\begin{array}{l}\text { Intravenous fluids and } \\
\text { antibiotics handling }\end{array}$ & Yes & No & Yes \\
\hline Days of hospitalization & 1 & 1 & 3 \\
\hline Operation & No & No & No \\
\hline \multicolumn{4}{|l|}{ Endoscopic findings } \\
\hline $\begin{array}{l}\text { Good endoscopic re- } \\
\text { section result (Ro re- } \\
\text { section) }\end{array}$ & Yes & Yes & Yes \\
\hline $\begin{array}{l}\text { Endoscopic signs for } \\
\text { perforation }\end{array}$ & No & No & No \\
\hline $\begin{array}{l}\text { Clips application in } \\
\text { EMR defect }\end{array}$ & No & No & No \\
\hline \multicolumn{4}{|c|}{ Radiological findings (CT imaging) } \\
\hline $\begin{array}{l}\text { Transmural thickening } \\
\text { and edema of the } \\
\text { bowel wall }\end{array}$ & Yes & No & Yes \\
\hline Intramural air bubbles & Yes & No & Yes \\
\hline $\begin{array}{l}\text { Localized collection of } \\
\text { intraperitoneal gas }\end{array}$ & No & No & Yes \\
\hline $\begin{array}{l}\text { Generalized pneumo- } \\
\text { peritoneum }\end{array}$ & No & Yes & No \\
\hline $\begin{array}{l}\text { Inflammatory strand- } \\
\text { ing in the surrounding } \\
\text { mesenteric fat }\end{array}$ & Yes & Yes & Yes \\
\hline $\begin{array}{l}\text { Free intraperitoneal } \\
\text { fluid }\end{array}$ & No & No & No \\
\hline \multicolumn{4}{|c|}{$\begin{array}{l}\text { (- absence of pain/tenderness, + mild pain/tenderness, }++ \text { moderate pain/ } \\
\text { tenderness, }+++ \text { severe pain/tenderness); CT, computed tomography; EMR, } \\
\text { endoscopic mucosal resection }\end{array}$} \\
\hline
\end{tabular}

age of the air bubble from the injectate outside of the colonic wall, during the multiple attempts with the EMR needle to lift the polyp with $45 \mathrm{ml}$ fluid in total. The needle was purged with liquid before the injection in order to avoid submucosal lifting with air, 2) The "balloon" phenomenon concerning the transmural passage of air or $\mathrm{CO}_{2}$ from the distended colon through a tiny hole that the EMR needle generates into the bowel wall, especially when the injectate is applied directly to the submucosa. Although the disappearance of the hole should be instantaneous, a small amount of air could pass transmurally into the 


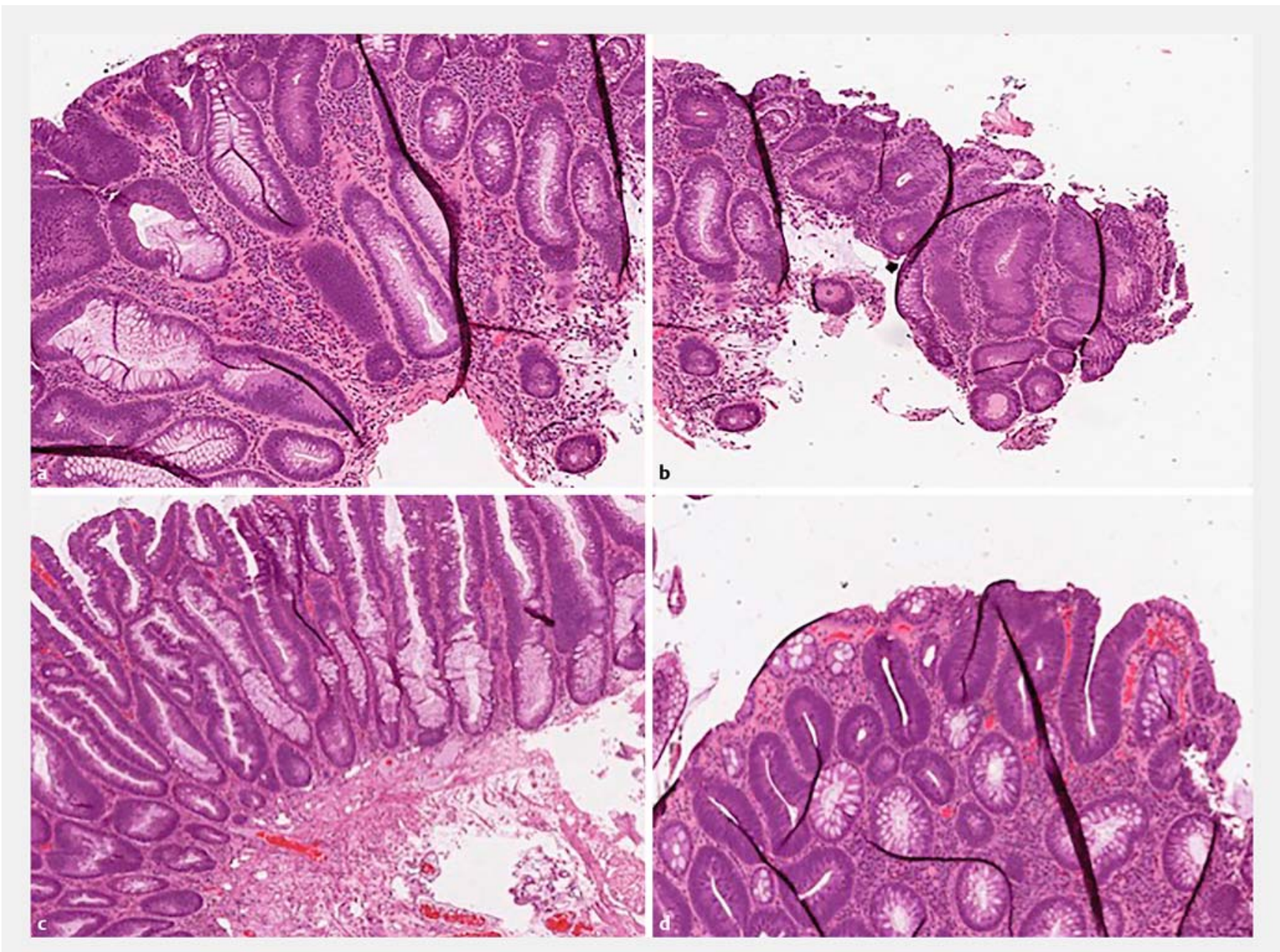

- Fig. 4 Histological image of fragments of the polyp showed a tubulovillous adenoma with high-grade dysplasia (a,d) and muscularis mucosa (MM) with submucosal tissue departmentally removed (b, c). Evidence for a cut or damaged muscularis propria (MP) in the specimen relevant to deep injury of the bowel wall during endoscopic mucosal resection (EMR) was not confirmed.

peritoneum and come to a stop when the pressure of the lumen flows, in the way a balloon leaks air when it is drilled with a pin.

We would like to highlight ( $\triangleright$ Table 1 ) the presence and the amount of free air after an EMR do not correlate reciprocally with patient's pain after the procedure and that a radiological diagnosis of perforation is not always a true perforation with presence of a hole. There are 2 previous publications with disproportional relation between the amount of extraluminal air and patient's pain after EMR procedure $[4,6]$. This was also true in our patient who had minimal gas with a small bubble outside the colon, but developed severe pain. We treated him conservatively because of the absence of a true endoscopic sign of perforation. Although we had the diagnosis for a covered perforation 1 hour after the procedure, we chose not to reevaluate endoscopically the patient for potential clip appliance (on time, $<4$ hours, concerning the ESGE guidelines [7]) in the absence of a real hole. Generally, the presence of extraluminal fluid and patient's clinical deterioration are much more serious situations, that require careful ongoing clinical review and surgical consultation.

\section{Conclusion}

We believe that colonic perforations after EMR without clear endoscopic evidence of a hole during the procedure should be considered as a DMI type 2 or 3 and should be initially treated conservatively regardless of the presence and the amount of peritoneal gas in CT imaging. EMR as an interventional procedure has signs and findings that are associated with the invasive character of the procedure, such as patient's pain and discomfort, radiological findings of intramural and/or extraluminal gas, colonic wall thickening and stranding in the adjacent fat. Endoscopists who often perform EMR should be familiar with them and treat the patient mainly according to his clinical condition by keeping always in mind the endoscopic view at the EMR site. Prompt surgical consultation is necessary to estimate patient's clinical condition and exclude possible deterioration. The decision-making for the treatment of a perforation after EMR could be based on a combination of the endoscopist's concept about the handling and the field during the resection, and the surgical opinion on the patient's clinical stage. Radiological 
imaging is essential in order to establish the diagnosis of a perforation but cannot solely guide the decision for repairing operation.

Competing interests

None

\section{References}

[1] Bourke M]. Endoscopic mucosal resection in the colon: a practical guide. Tech Gastrointest Endosc 2011; 13: 35 - 49

[2] Swan MP, Bourke M], Alexander S et al. Large refractory colonic polyps: is it time to change our practice? A prospective study of the clinical and economic impact of a tertiary referral colonic mucosal resection and polypectomy service (with videos) Gastrointest Endoscopy 2009; 70: $1128-1136$

[3] Heldwein W, Dollhopf M, Rosch T et al. The Munich Polypectomy Study (MUPS): prospective analysis of complications and risks factors in 4000 colonic snare polypectomies. Endoscopy 2005; 37: 1116 1122

[4] Stephenson JA, Crookdake J, Jepson S et al. Imaging findings postcolorectal endoscopic mucosal resection. J Radiol Case Rep 2013; 7 : $27-32$

[5] Ma MX, Bourke M]. Complications of endoscopic polypectomy, endoscopic mucosal resection and endoscopic dissection in the colon. Best Pract Res Clin Gastroenterol 2016; 30: 749-767

[6] Heerasing N, Dowling D, Alexander S. Abdominal pain post endoscopic mucosal resection: Treat the patient not the CT scan. World ] Gastrointest Endosc 2013; 16: 455 - 456

[7] Paspatis GA, Dumonceau JM, Barthet $M$ et al. Diagnosis and management of iatrogenic endoscopic perforations: European Society of Gastrointestinal Endoscopy (ESGE) Position Statement. Endoscopy 2014; 46: 693 - 711 